\title{
Call for papers and preliminary registration
}

\section{7th International IUFRO Wood Drying Conference Tsukuba, Japan, July 9-13, 2001}

\author{
Conference theme: Moisture control in environment-friendly housing and \\ wood-drying technology in the new century
}

See the announcement of details in Mokuzai Gakkaishi 46 (3)

\section{Mokuzai Gakkaishi (Journal of the Japan Wood Research Society)}

Mokuzai Gakkaishi is another official journal of the Japan Wood Research Society. This journal publishes original articles, notes, review articles, and announcements from the Society in Japanese but with English abstracts, tables, and figure captions for original reports. Contents of the latest issue of Mokuzai Gakkaishi are as follows:

Volume $46 \quad$ Number 32000

Original articles

M. Yokoyama, K. Kanayama, Y. Furuta, M. Norimoto

Mechanical and dielectric relaxations of wood in a low temperature range III: Application of sech law to dielectric properties due to adsorbed water

\section{K. Ikeda, N. Kino}

Quality evaluation of standing trees by a stresswave propagation method and its application I: Seasonal changes of moisture contents of sugi standing trees and evaluation with stress-wave propagation velocity

K. Ikeda, T. Arima

Quality evaluation of standing trees by a stresswave propagation method and its application II: Evaluation of sugi stands and application to production of sugi (Cryptomeria japonica D. Don) structural square sawn timber

Y. Kodama, Z. Zhang

Evaluation of wood quality by wavelet analysis I: Wavelet analysis of the tapping tone of wood with a knot

K. Nakata, H. Sugimoto, M. Inoue, S. Kawai Development of compressed wood fasteners for timber construction IV: Moment resistance of a joint model with a compressed LVL plate and effect of reinforcement by glass fiber sheets

M. Harada, T. Hayashi, M. Karube

Effect of deformation rate on bearing properties of mechanical joints of LVL with a draft pin
M. Kishino, H. Ohi

Cleavage of $\mathrm{C} \alpha-\mathrm{C} \beta$ bonds of lignin model compounds by nitrite and nitric acid II: Degradation of a nonphenolic $\beta-5$ type lignin model compound

\section{S. Nagahama, T. Iwaoka, T. Ashitani}

Terpenoids of the wood oil of sugi (Cryptomeria japonica) VI: Components of elite clones KenKma-3, KenKoyu-3 and KenAira-14

A. Takagaki, K. Fukai, F. Nanjo, Y. Hara,

M. Watanabe, S. Sakuragawa

Application of green tea catechins as formaldehyde scavengers

\section{Notes}

T. Fujimoto, T. Nakano

The effect of mercerization on wood structural features

N. Sobue, K. Matsuo, K. Ikeda

Effect of depth of a sawn slit parallel to the fiber direction on shear modulus of commercial size square timbers

M. Nakayama, C. Tanaka, T. Ohtani, H. Usuki Studies on a measurement method of surface roughness in wood machining I: The effect of stylus types on the roughness profiles

Y. Hirashima, T. Nishi

Indoor climate of a $\log$ structure elevated on columns 